\title{
UNCLĀSSIFIED
}

RECORDS ADMINISTRATION

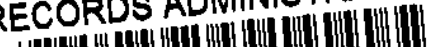

FROM FILE

DIFFERENTIAL ELECTROMETER

by

A. C. Lapsley

Instrument Development Division

December 1954

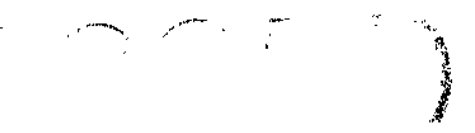

25

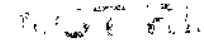

reck

E. I. du Pont de Nemours \& Co.

Explosives Department - Atomic Energy Division

Technical Division - Savannah River Laboratory 


\section{DIFFERENTIAL ELECTROMETER}

by

A. C. Lapsley

Instrument Development Division

December 1954

E. I. du Pont de Nemours \& Co.

Explosives Department - Atomic Energy Division

Technical Division - Savannah River Laboratory

Printed for

The United States Atomic Energy Commission

Contract AT $(07-2)-1$ 


\section{INTERNAL DISTRIBUTION}

(5) AEC, SROO

(1) L. Squires - H. Worthington

(1) ${ }^{\mathrm{D}} \cdot \mathrm{W}$ " $\mathrm{F} 1 \mathrm{Babcock}$

(1) J. A. Burns

(1) W. P. Overbeck -

(1) T. C. Johnson - J. D. Cist

2) M. M. Mann

5 P. S. Shane

i) H. J. Bowman - W. M. Sloan

5 R. H. Dietz

(1) W. S. Church - K. W. French

(1) H. E. Ostdahl

1 W. E. Winter

I G. E. McMillan

(1) I. R. Smith

(1) E. H. Judkins

(1) M. H. Wahl -

C. W. J. Wende

(1) J. W. Croach -

L. M. Arnett

(1) G. Dessauer - J. I. Crandall

I.) J. N.WIIson

1) I. Cathey

1) J. L. Hyrde

(1) A. C. Lapsley

(15) TIS File

(1) TIS File Record Copy
Augusta, Ga.

Wilmington, AED

11

Engineering Department

Savannah River Plant

11

11

11

II

II

$n$

It

If

II

Savannah River Laboratory

\section{"}

"1

II

II

II

II

11 


\section{ABSTRACT}

An electrometer was developed to measure the amplitude of low frequency modulations of small direct current signals. The accuracy of the measured $A C / D C$ ratio is $\pm 2 \%$ for modulation frequencies less than $1 / 4$ cps and amplitudes greater than $0.3 \%$ of the DC signal. The full-scale DC range is from 10-9 to $10^{-5}$ ampere.

External Distribution according to TID-4500, (8th edition). 
$D P-95$

Page 3

TABLE OF CONTENTS

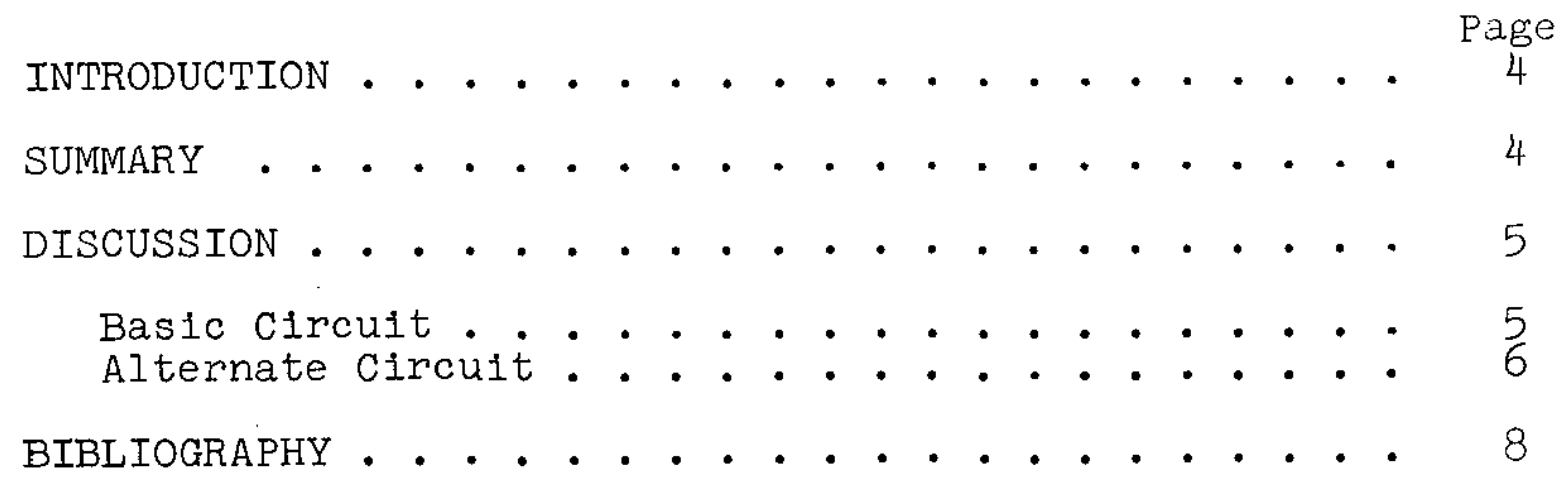

LIST OF FIGURES

Figure 1. Block Diagram of Differential

Electrometer ........... . 9

Figure 2a. Schematic Wiring Diagram of Amplifier
and Detector Sections . . . . . . . 10

Figure 2b. Schematic Wiring Diagram of Power

Figure 3. Differential Electrometer panel $\dot{*}^{*} \cdot \bullet^{*} \cdot \bullet^{*} \quad 11$

Figure 4. Block Diagram of Alternate

Electrometer Circuit . . . . . . . 12 
DP -95

\section{INTRODUCTION}

J. M. Harrer et al! (I), at Argonne National Laboratory, developed a method for determining the transfer functions of a nuclear reactor. They osclilated a neutron absorber and measured the amplitude of the power level changes with an ion chamber and a differential electrometer circuit.

Similar measurements were performed at the Savannah River Plant by oscillating control rods. The method required that reactor perturbations be kept small, and therefore the amplitude of the ion chamber current oscillations was small. Since there were no commercially available instruments which could measure the amplitude to the desired accuracy, a special electrometer was required.

\section{SUMMARY}

A differential electrometer was developed that may be used to record the amplitude of power level oscillations of a nuclear reactor by measuring the modulated output current of an ion chamber. The accuracy of the measured $A C / D C$ ratio is $\pm 2 \%$ for modulation frequencies less than $1 / 4$ cps and amplitudes greater than $0.3 \%$ of the DC signal. The full-scale DC range is from $10^{-9}$ to $10^{-5}$ ampere. On the lowest range a total input capacitance smaller than $20 \mu \mu \mathrm{f}^{\circ}$ is required to prevent attenuation of a $1 / 8 \mathrm{cps}$ modulating signal.

The electrometer performance is satisfactory, and no further development work is planned. 


\section{DISCUSSION}

Oscillations in pile power, produced by oscillating the control rods, resulted in an ion chamber current whose $\mathrm{AC}$ component had a triangular wave form with an eight-second period. The peak-to-peak amplitude was $0.3 \%$ to $3 \%$ of the DC component.

The differential electrometer, which was built to measure currents of this nature, operates in the following manner. The input current develops a voltage across a reference resistor, and this voltage is amplified with a DC amplifier. A bucking voltage is applied to the amplifier output to cancel the DC component of the amplified signal. The remaining signal, which follows the oscillations, is accurately readable. Use of a regulated power supply and stable circuit components prevents the drift of this signal from exceeding five per cent of full-scale per minute. Any error which the drift introduces is easily averaged out.

\section{BASIC CIRCUIT}

A block diagram of the electrometer is shown in Figure 1. The input current flows through the reference resistor $R_{r}$ and the voltage developed across it is amplified by a three-stage $D C$ amplifier, patterned after a circuit designed at ORNL (2). The amplifier thus develops an output voltage proportional to the ion chamber current. When the double-pole, double-throw switch is in position "A", the amplifier output sends a current through the microammeter. This current is limited by the resistor $R_{A}$, and its magnitude is proportional to the power level of the pile.

When the switch is thrown to position "B", one of its poles inserts a limiting resistor of lower value, $R_{B}$, into the meter circuit to increase the meter's sensitivity. The other pole applies a bucking voltage to the amplifier output which is of the proper value to keep the meter on scale. The meter then "sees" and follows only the alternating component of the amplifier output. The net travel of the meter needle is proportional to this component, and thus to the peak-to-peak amplitude of the power level oscillations. The ratio of the limiting resistors $R_{A}$ and $R_{B}$ is known, and the ratio between the power oscillations and total power level can be calculated.

A strip chart recorder is connected in series with the meter for greater accuracy in the measurements. The penspeed of the recorder determines the minimum period at which accurate data are obtainable. On a recorder requiring one second for the pen to travel across the chart, the minimum readable period is in the order of four seconds. 
The schematic wiring diagram of the electrometer is shown in Figure 2. A photograph of the electrometer is given in Figure 3, which shows both electrometer panel and the recorder.

Two features of the wiring diagram deserve special mention: (1) The meter circuit switch S3, which was represented by the double-pole, double-throw switch in Figure 1, actually has five positions as shown in Figure 2. The successive positions increase the meter sensitivity in alternate steps of 3 and $3-1 / 3$ and allow coverage of all modulations which are greater than $0.3 \%$ of the base current. (2) The potentiometer on the V2 cathode (R7 in Figure 2) is a dual-purpose control. It is used as a zero control, and also as a vernier adjustment to keep the meter and recorder on scale while the steady-state current is being bucked out.

The electrometer does not operate satisfactorily at input currents less than 10-9 ampere. The threshold is limited by the input capacitance which shunts the reference resistor of the electrometer and lowers the overall input impedance. If a 10-9-ampere DC current is to be measured, the $5.1 \mathrm{x} 10^{8}$-ohm reference resistor should be used. If the shunting input capacitance is 20 micro-microfarads, the corresponding impedance at $1 / 8 \mathrm{cps}$ is $6 \mathrm{x} 1010 \mathrm{ohms}$. This value, in confunction with lower impedances for the higher harmonics present in the triangular-shaped wave, is sufficient to attenuate and distort the signal.

\section{ALTERNATE CIRCUIT}

Another differential electrometer circuit was also built and tested. An ion chamber and its power supply were connected to form two legs of a bridge circuit, while the other two legs were formed by a second power supply and a resistor. A Beckman Model V micro-microammeter was placed across these legs so as to measure the difference in current between them. A block diagram of this circuit is shown in Figure 4.

This circuit as built did not correctly indicate the peak-to-peak amplitude of the modulating signal at $1 / 8$ cps frequency. The meter circuit of the Beckman micromicroammeter had a time constant too great to follow this signal accurately. (Reference may be made to the Beckman Bulletin 271-B for the wiring diagram of the micromicroammeter).

A change of the Beckman circuit to eliminate the 3000 microfarad condenser across its feedback resistor network should overcome the time constant difficulty. The resulting electrometer would probably work satisfactorily with input capacitances about 1000 times larger, or voltages 
1000 times smaller, than can be tolerated with the present instrument, because the feedback clrcuit built into the Beckman micro-microammeter degeneratively lowers its input impedance. Thus a superior instrument might result from development of this alternate circuit.

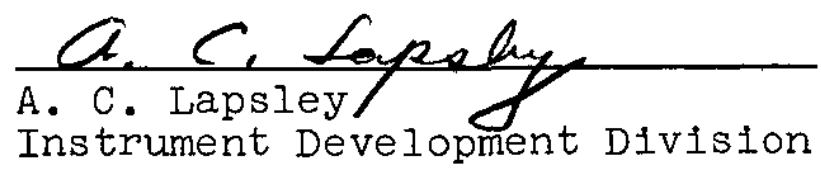




$$
\begin{aligned}
& \text { DP - } 95 \\
& \text { Page } 8
\end{aligned}
$$

\section{BIBLIOGRAPHY}

1. Harrer, J. M., Boyar, R. E., and Krucoff, Darwin. Measurement of CP-2 Reactor Transfer Functions. Argonne National Laboratory ANL 4373, January 1, 1950.

2. Jordan, W. H., Frey, H. B., and Kelley, George. An Instrument for Measuring the Logarithm of Neutron Level and the Period of a Pile. Oak Ridge National Laboratory ORNL-110, November 23, 1948 (Declassified February 16, $1954)$. 


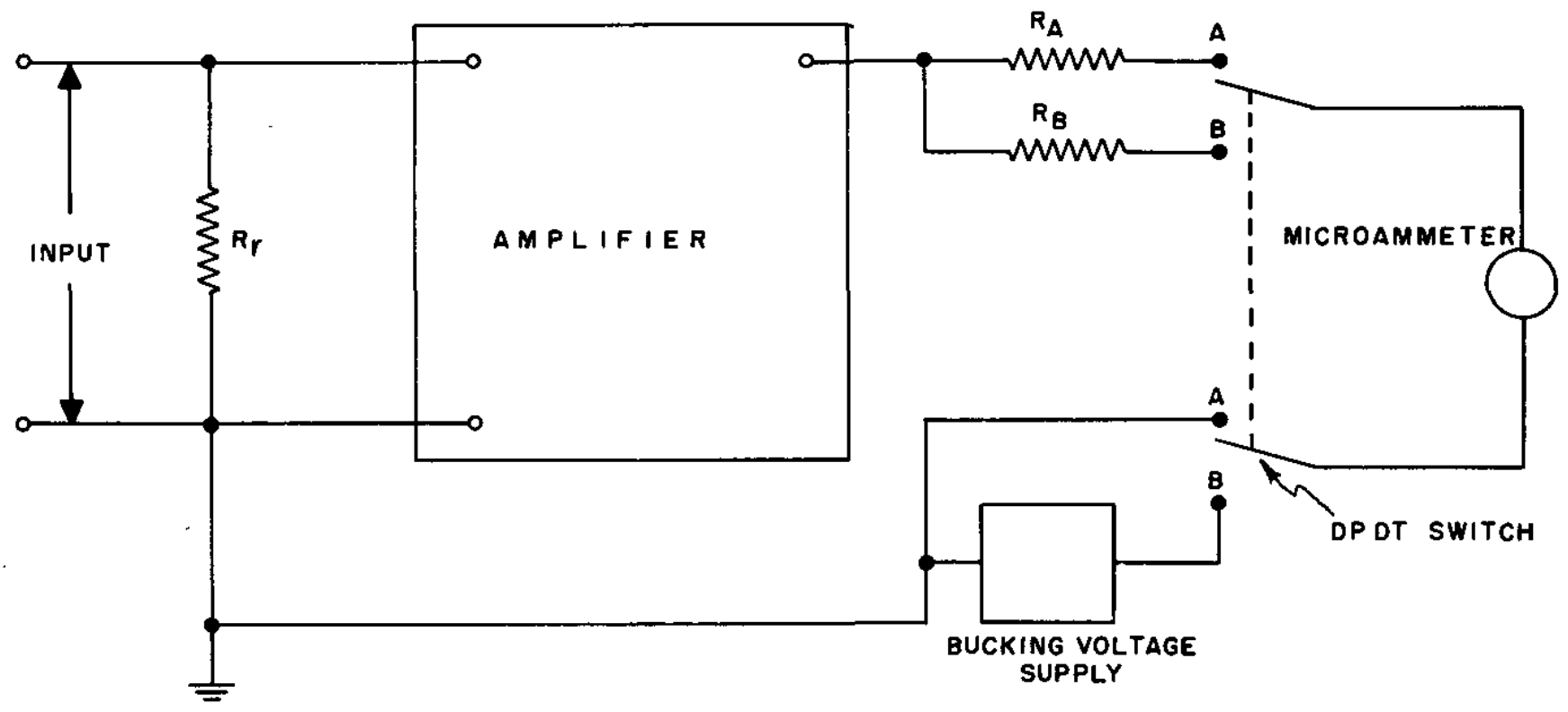




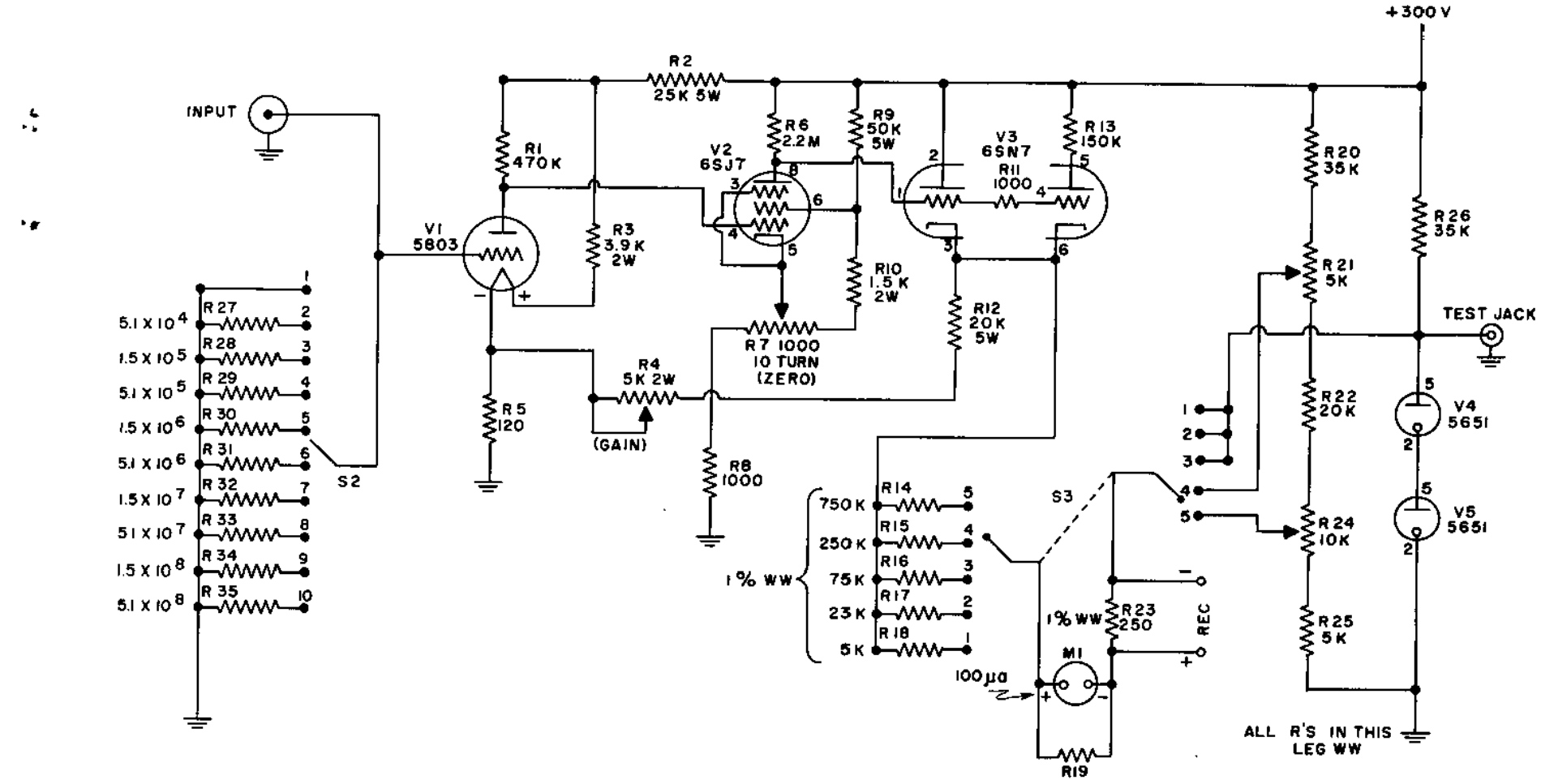

SCHEMATIC WIRING DIAGRAM OF AMPLIFIER AND DETECTOR SECTIONS

$\therefore$

FIGURE 2b

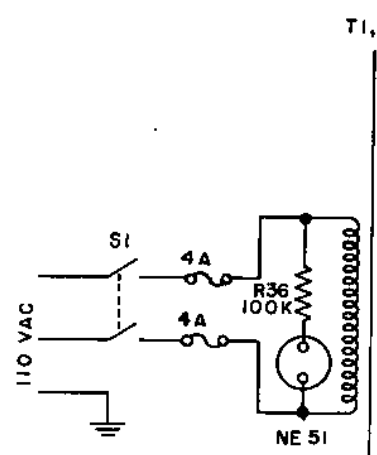

TI, T22R33

8h, $75 \mathrm{mo}$
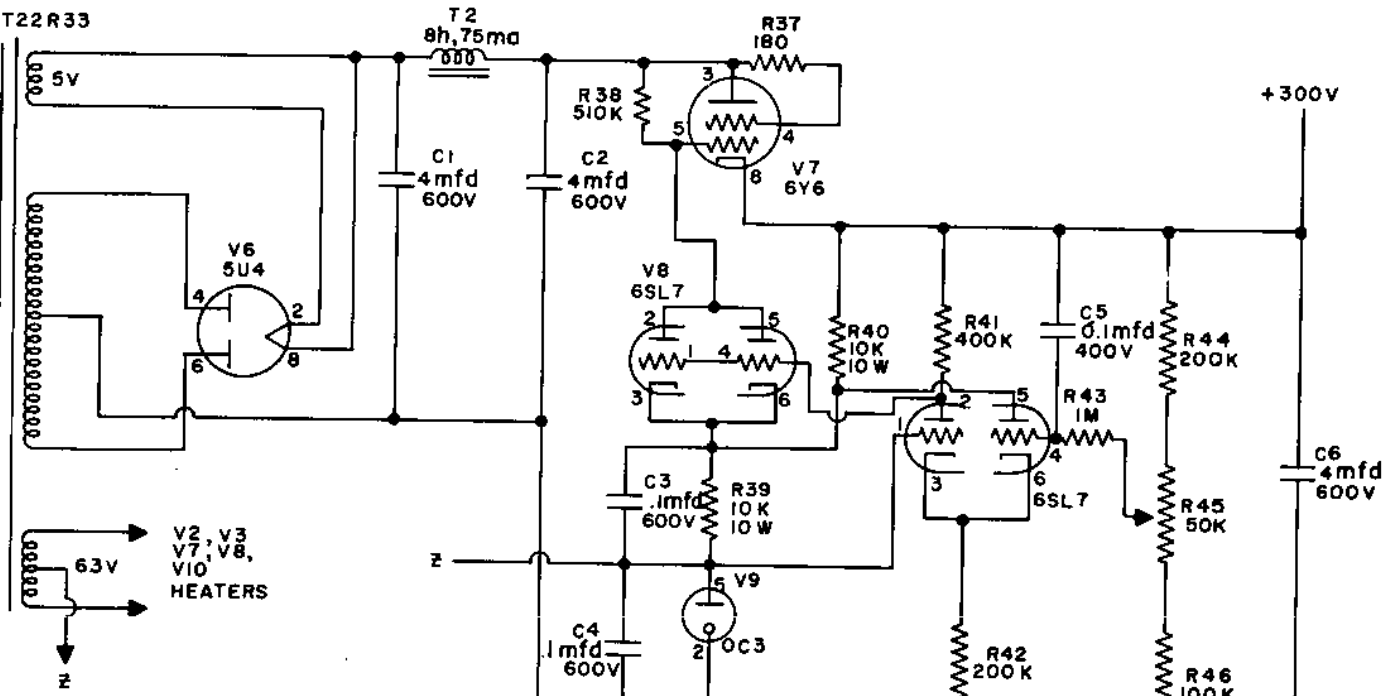


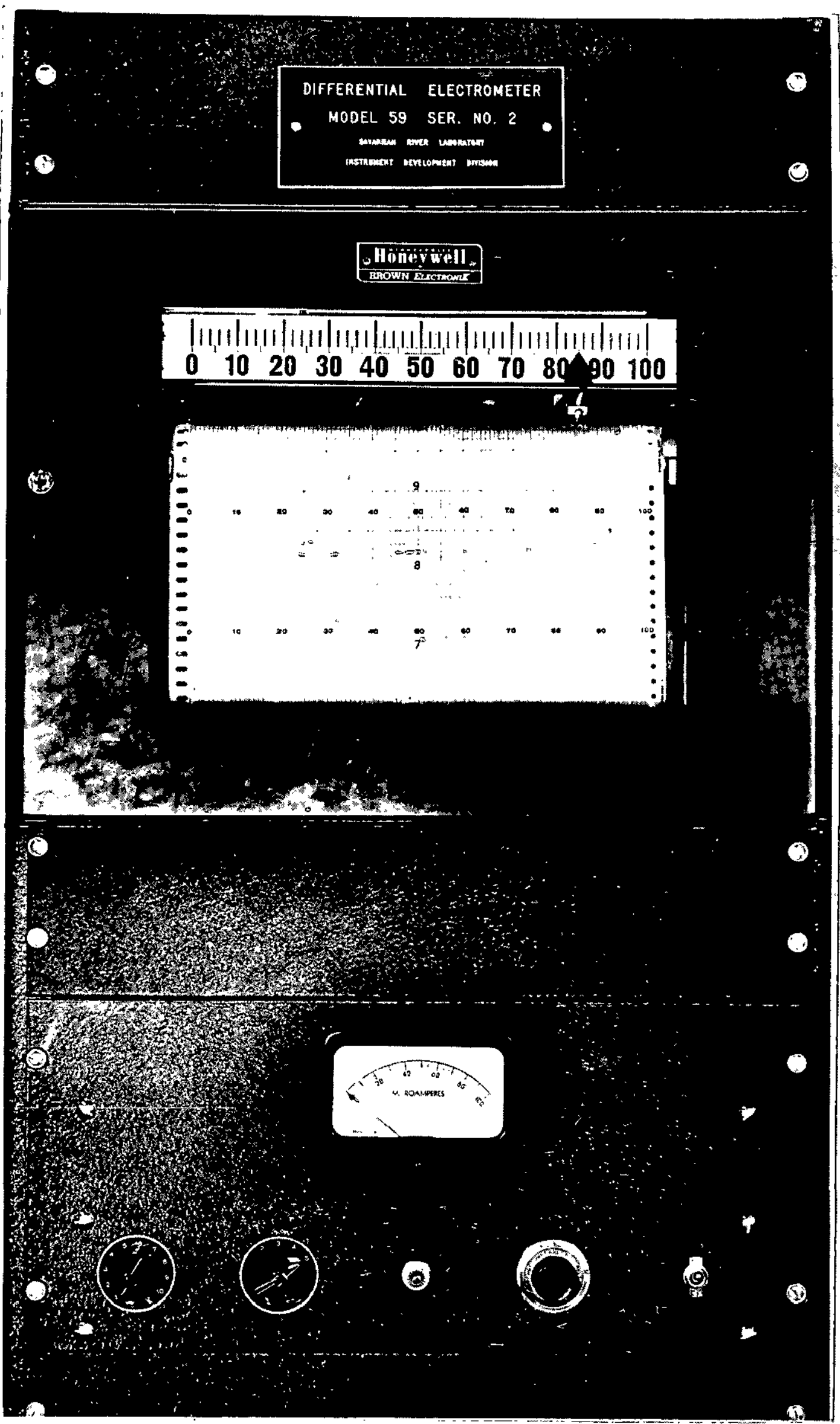




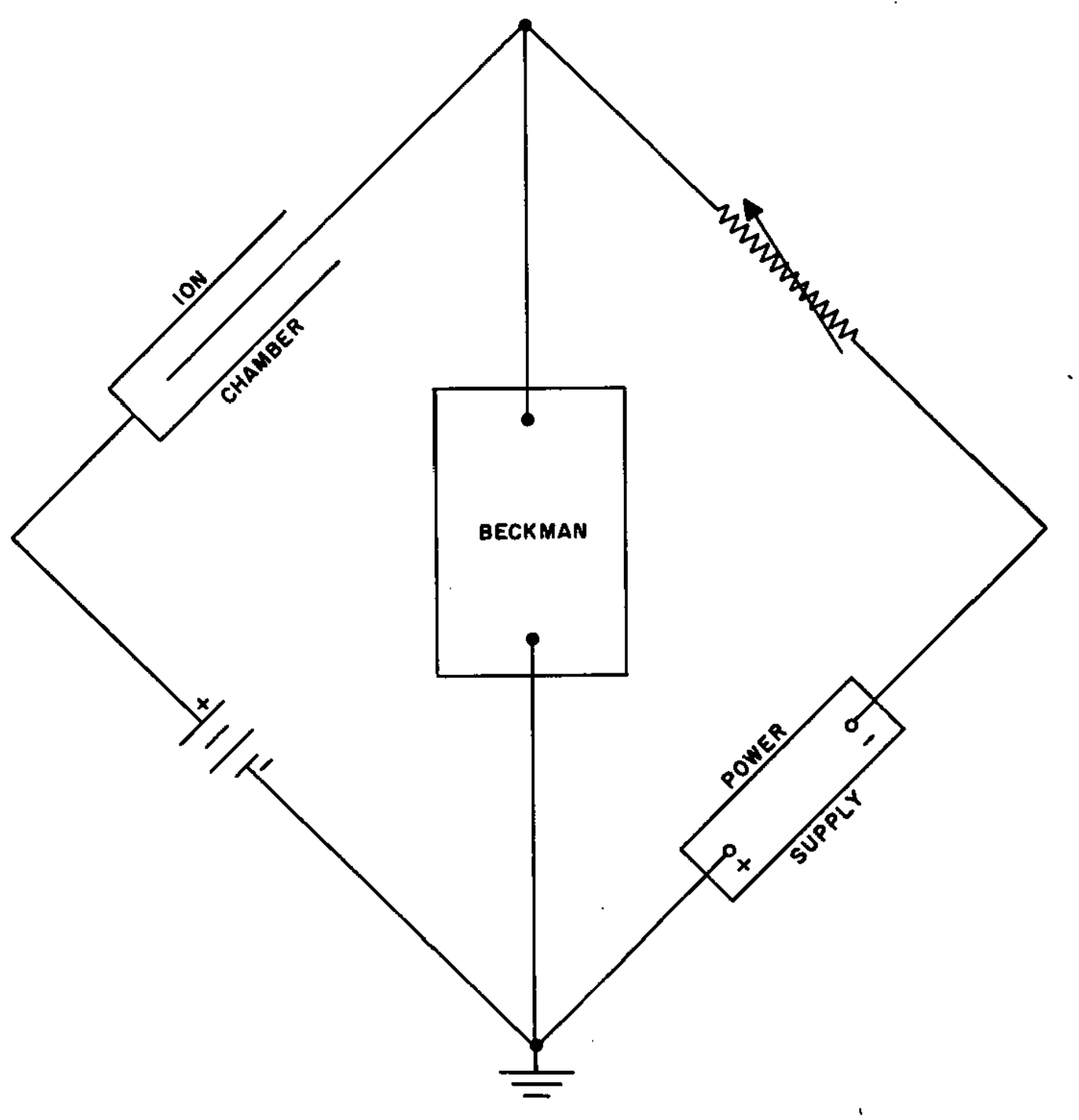

